\title{
Development of firing pin and breech face impression on lead and plasticine surfaces- a case report
}

\author{
Devinderpal Singh Sehgal, Sandeep Singh Sahota*, Navneet Kaur and Arshdeep Kaur
}

\begin{abstract}
Background: The microscopic examination of fired cartridge cases and fired bullets helps the expert to determine if a suspect firearm/firearms were, or were not, discharged in a shooting incident. This is achieved by using a combination of class and individual characteristics. But in case of malfunctioning of firearm, experts have to adopt different methods to link fired cartridge cases and fired bullets with the suspected firearm.

Case presentation: In this paper, a new method for the reproduction of the firing pin and breech face impression on two different surfaces are reported. Two chosen surfaces are plasticine and lead metal.

Conclusions: The surface of the lead being soft and brittle reproduced the impression with maximum detail. Five match points were seen on the lead surface with clear demarcation whereas only three points of individual characteristics marks were observed on plasticine surface.
\end{abstract}

Keywords: Plasticine, Lead, Pistol, Impression, Breech face, Firing pin

\section{Background}

Linking of the firearm, fired cartridge case and bullet is a classical example of tool mark identification. It follows the forensic science basic principle of individuality that no two tools marks should produce the same microscopic marks on two separate objects that they would be inaccurately or wrongly identified (Smith et al., 2016). Fired cartridge cases and bullets bear characteristic marks, which enable firearm examiners to identify the firearm that fired them (Kinder et al., 2004). Examination of firing pin and breech face impression on the fired cartridge case is essential link for the linkage of firearm with the fired cartridges (Sharma, 1963). But in few cases it becomes difficult to match the fired cartridge with the alleged firearm due to malfunctioning of firearm or in cases where the firearm misfires live test cartridges. In such cases the firing impressions could be reproduced on various soft surfaces without damaging the firing pin. Firing pin impressions are generated because of striking of firing pin on the percussion cap of the cartridge. Similarly breech face impression are

\footnotetext{
*Correspondence: singhsandeep96@gmail.com

Punjab Forensic Science Laboratory, Phase-IV, Mohali, Punjab, India
}

obtained when a cartridge is fired in the gun the very heavy pressure of the gas generated inside the cartridge force the head of the cartridge back against the head of the breech block which imprints the impression on the breech on the brittle material commonly brass or germanium silver (Harding-Barlow, 1950).

In this paper, the breech and firing impression were reproduced on different surfaces to match the impression with the fired shell. First surface selected is Plasticine. Plasticine is a trademark name for an oil-based modeling material that was developed in England in 1897. Unlike clay and wax, plasticine stays soft and workable: it neither hardens nor dries (http://www.kirkside.com.au/Uploads/ Images/plasticene.pdf). It has wide range of application in forensic science. It has been used successfully in examination of footwear impression (Morgan et al., 2009), facial reconstruction (Stephan \& Henneberg, 2001; Benazzi et al., 2009; Claes et al., 2006; Cesarani et al., 2004; George, 1987), forensic ballistics (Jain et al., 2004; Hejna \& Safr, 2009), restoration of obliterated marks (Kuppuswamy, 2011), tool mark impression (Rees, 1969) and Odontology (Gorea et al., 2007).

The second surface selected for the study is lead. It is heavy, soft, bluish metal, and occurs in nature in the 
form of ores. Being soft the marks could be easily reproduced on lead and it could be used as a surface for reproduction of marks. These findings are put into context for the comparison of cartridge cases.

\section{Case presentation}

A case for linking of fired cartridge with a country made pistol having a broken barrel was received in Punjab Forensic Science Laboratory, Mohali, Punjab (India). The length of the country made pistol was $15 \mathrm{~cm}$ and a weight of $0.670 \mathrm{~g}$ (Fig. 1). It had a single column, box-type magazine with a capacity of 12 rounds and was designed to fire $7.65 \mathrm{~mm}$ cartridges. No land and groove were present inside the barrel of the firearm. Length of the barrel was $7 \mathrm{~cm}$ but the barrel of the firearm was found broken (Fig. 2). Five $7.65 \mathrm{~mm}$ test cartridges were fired through the country made pistol, but it misfired all the test cartridges, leaving a minute impression without sufficient detail for comparison with crime cartridge case. So, the firing pin and breech face impressions were successfully reproduced on two surfaces for comparison with fired crime cartridge case.

\section{Experimental}

\section{Equipment}

Leica FSC comparison microscope with Leica DFC320 camera (Switzerland) was used for the comparison of marks. Leica application suite software version 3.7.0 was used for the processing of the processing of the data. Afcoset electronic balance (ER-18 2A, Bombay Burmah trading Corp, Ltd., India) was used for weighing of the materials.

\section{Materials}

Experimental firings were conducted through a country made pistol (Fig. 1), K.F. S\&WL, Indian Ordnance Factory, Kirkee (Pune, India) manufactured cartridges. Plasticine was purchased from local shop. Lead metal was obtained from the lead bullet by removing it using a bullet puller.

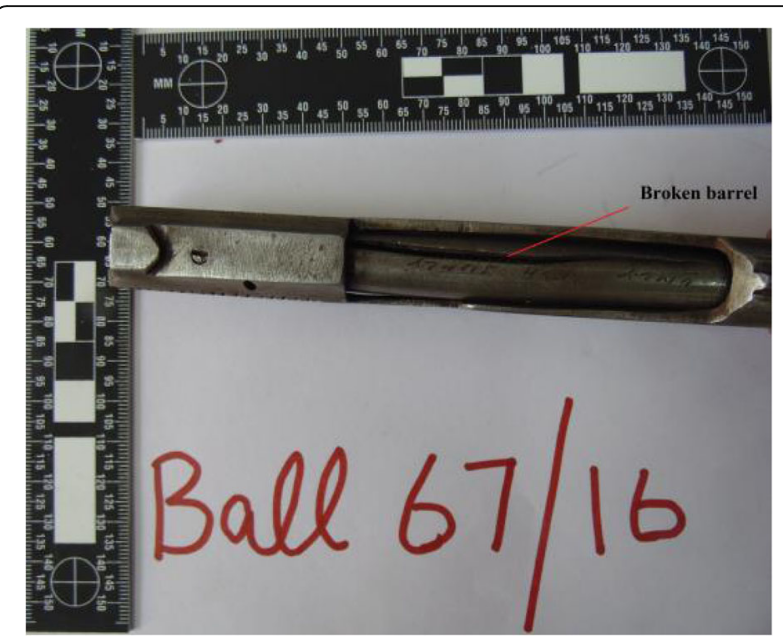

Fig. 2 Showing broken barrel of country made pistol (India)

\section{Impression surfaces}

The surfaces chosen for the reproduction of the firing pin and breech face impression were lead and plasticine. These surfaces were chosen due to tendency of being softer than firing pin and breech face and the marks could be easily reproduced without destroying the original surface. The surface of firing pin and breechface were cleaned with acetone to remove dust material adhered to it and then plasticine/lead were pressed against firing pin and breechface surfaces the surface impression.

\section{Preparation of cast}

For the preparation of the impression of the firing pin and breech face two surfaces were selected. First surface was placticine. Plasticine was pressed against the hard surface of the firing pin and breech face to reproduce the surface impression.

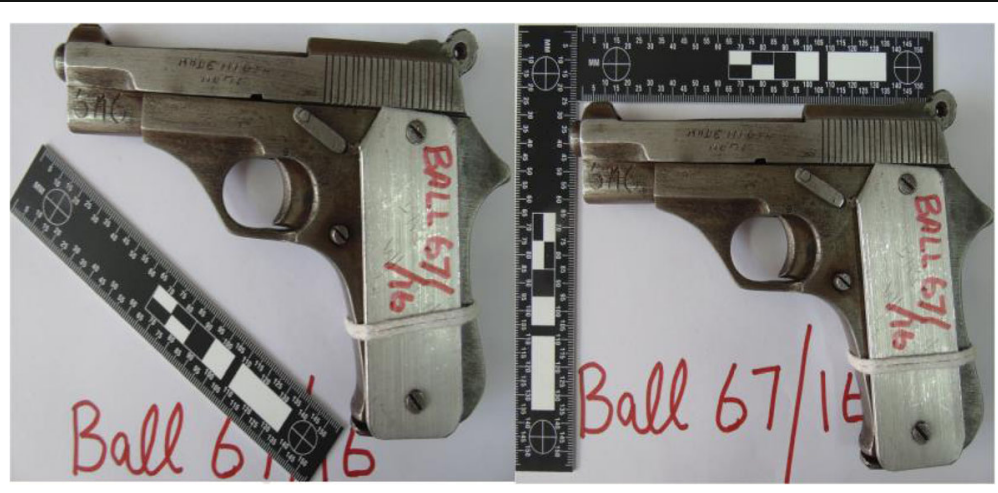

Fig. 1 Showing dimension of country made pistol (India) 
The second surface selected was lead metal. It was obtained from lead bullet of 0.32 in. by removing it using bullet puller and then hammered and flattened. Lead/plasticine were pressed on breech face to collect the firing pin and breechface impressions. Being a soft material the impression of the firing pin and breech were reproduced on the lead/plasticine material. A flow chart showing methodology of case study is shown in Fig. 3.

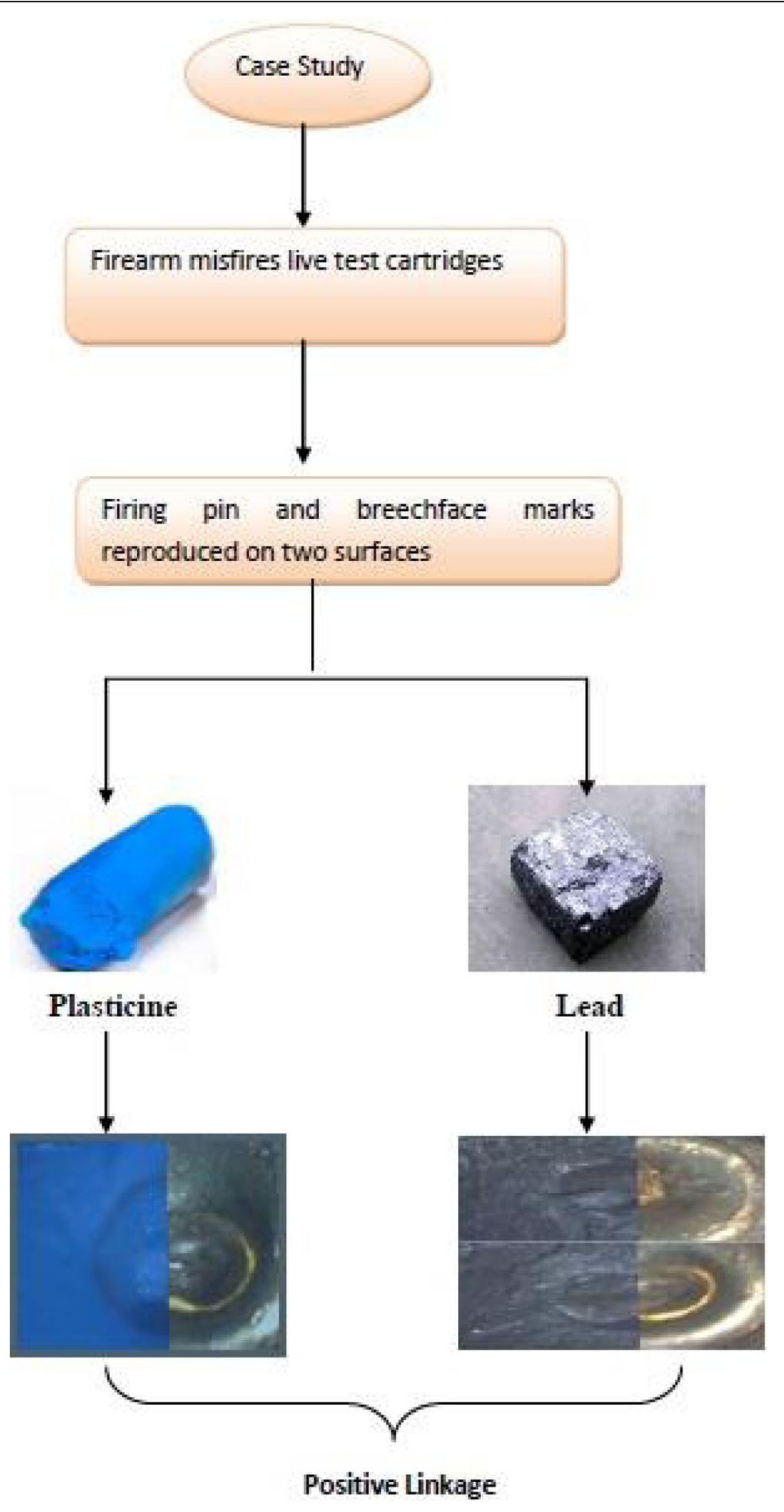

Fig. 3 Showing flow chart of methodology adopted 


\section{Results and discussion}

Various casting methods (Plaster, Moulage, Faxfilm (Cowres, Davm L, Dodge, James K. A Method for Comparison of Tool Marks, 1948; Science and Practice Committee Report, 1949), plasticine (Kirk, 1953; O'hara \& Osterbtrn, 1949), thermoplastics (Kirk, 1953), wax and electroplating (Tarko, 1948)) have been proposed for reproduction and comparison of individual characteristics marks on fired cartridge cases as an aid to firearms and tool mark identification. Most of the proposed methods had little or limited success due to timeconsuming techniques and unsatisfactory results. In 1938, Moritz proposed a technique utilizing cellulose acetate with an acetone or amyl-acetate vehicle for the reproduction and comparison of the individual characteristics on cartridge cases, bullets and breech faces (Morrrz, 1938; Biasotti, 1956). The only advantage of the technique was preparation of flexible, translucent cast that could be flattened and viewed by transillumination thus reducing or obviating the difficulties inherent in the direct observation of curved or inaccessible surfaces by reflected illumination. Later, Faxfilm (trade name) became a commercial adaptation of the technique proposed by Moritz. It had larger application in studying the quality of finish on machined metal parts. The use of Faxfilm in law enforcement work has been reported, but literature on its practical application is meager (Science and Practice Committee Report, 1949; Biasotti, 1956). Cowles and Dodge have reported the successful application of Faxfilm to tool mark recovery and comparison and have pointed out its limitations when applied to deep impressions or to painted surfaces (Cowres, Davm L, Dodge, James K. A Method for Comparison of Tool Marks, 1948). Later another method for to form replicas of the fired bullets were proposed using sheets of vinyl thermoplastic varying in thickness from 0.030 to 0.125 " (depending on the depth of the mark). The disadvantage of the method was the application of heat (100 to $125{ }^{\circ} \mathrm{C}$.) and pressure (Kirk, 1953). An infrared lamp or electric hot plates were used for heating. These replicas were flattened and viewed by transillumination as either a positive or negative image. Accurate, reproducible replicas, free from air bubbles, shrinkage, and warping were obtained. However, the necessity of applying heat and pressure simultaneously, which may not be a serious disadvantage in the laboratory, makes this method rather impractical to use at the crime scene in the recovery of tool marks. Another material commonly used for lifting firing pin impression is plasticine, it is also used for replication of rifiling marks of fired bullet (Jain et al., 2004).

In the present study, plasticine and lead surfaces were used. The advantage of current method with previous methods reported is accurate, reproducible replicas, free

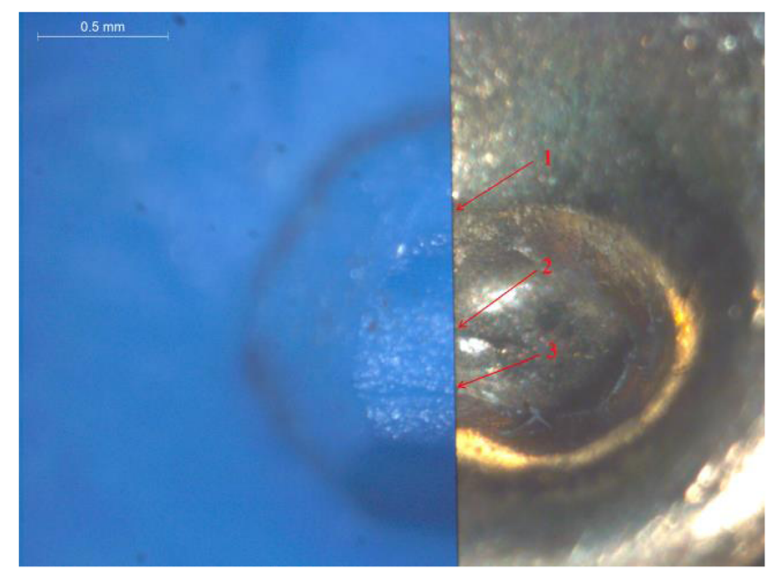

Fig. 4 Showing comparison of firing and breech face marks on cartridge case with impression on plasticine (magnification $10 \times 2=20 \times$ )

from air bubbles and non application of heat and pressure for reproduction of marks. On comparison of firing pin and breech face impression of crime cartridge case with the impression of firing pin and breech face taken on plasticine. Three points in a match were found to be reproduced on the plasticine impression. Point- 1 shows the periphery of the firing pin. Point-2 shows a horizontal line passing through the middle of firing pin impression. Point-3 shows a line at 7 O'Clock position (Fig. 4). However, the same impression was reproduced on lead surface was much pronounced than plasticine surface. Five match points were seen on the lead surface with clear demarcation (Fig. 5). Point-1 shows firing pin impression at 12 O'Clock position. Then moving down point- 2 is a line at 2 O'Clock position. Point- 3 shows an arc at 3 O'Clock position. In the middle a line crossing

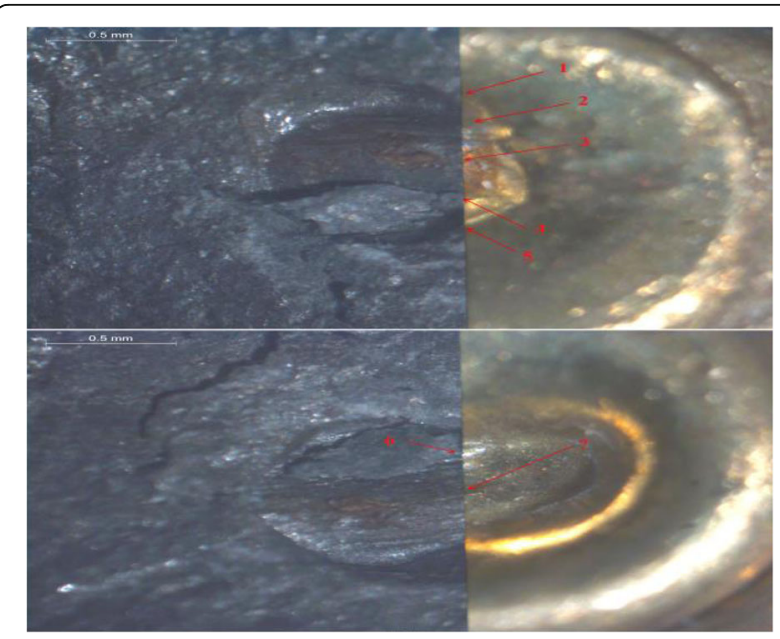

Fig. 5 Showing comparison of firing pin and breech face marks on cartridge case with impression on lead (magnification $10 \times 2=20 \times$ ) 
shows point- 4 . Point- 5 is again a clear demarcation of firing pin impression at 6 O'Clock position.

\section{Conclusion}

On the comparison of marks on two substrates, lead was found most suitable surface for the reproduction of marks as lead surface gave more detail as compared to the plasticine. Further research could be carried out exploring different surface for the successive reproduction of the marks of firing pin and breech face in case of malfunctioning of firearm.

\section{Acknowledgements}

We are thankful to Director, Punjab Forensic Science laboratory, Mohali for her support.

\section{Funding}

Not applicable.

Availability of data and materials

Not applicable.

\section{Authors' contributions}

Each author has contributed equally in the preparation of manuscript and work. All authors read and approved the final manuscript.

\section{Ethics approval and consent to participate}

Not applicable.

Consent for publication

Not applicable.

\section{Competing interests}

The authors declare that they have no competing interests.

\section{Publisher's Note}

Springer Nature remains neutral with regard to jurisdictional claims in published maps and institutional affiliations.

Received: 31 May 2017 Accepted: 27 September 2017

Published online: 18 October 2017

\section{References}

Benazzi S, Fantini M, Crescenzio FD, Mallegni G, Mallegni F, Persiani F, Gruppioni G (2009) The face of the poet Dante Alighieri reconstructed by virtual modelling and forensic anthropology techniques. J Archaeol Sci 36:278-283 Biasotti AA (1956) Plastic Replicas in Firearms and Tool Mark Identifications. J Crim L Criminology \& Police Sci 47:110-117

Cesarani F, Martina MC, Grilletto R, Boano R, Maria A, Roveri D, Capussotto V, Giuliano A, Celia M, Gandini G (2004) Facial Reconstruction of a Wrapped Egyptian Mummy Using MDCT. Am J Roentgenol 183:755-758

Claes P, Vandermeulen D, Greef SD, Willems G, Suetens P (2006) Craniofacial reconstruction using a combined statistical model of face shape and soft tissue depths: Methodology and validation. Forensic Sci Int 159:S147-S158

Cowres DL, Dodge JK (1948) A Method for Comparison of Tool Marks. J Crm law am Crn 39:262-264

George R (1987) The Lateral Craniographic Method of Facial Reconstruction. J Forensic Sci 32:1305-1330

Gorea RK, Jasuja OP, Aggarwal AD, Narula R (2007) Revenge by the Bites. J. of Indian Acad. of Forensic Med 29:17-20

Harding-Barlow M (1950) Firearms Identification as a Science. Ann Surv S African L 67:379

Hejna P, Safr M (2009) An Unusual Zip Gun Suicide—Medicolegal and Ballistic Examination. J Forensic Sci 55:254-257

Jain SK, Singh BP, Singh RP (2004) Indian homemade firearm —a technical review. Forensic Sci Int 144:11-18
Kinder JD, Tulleners F, Thiebaut H (2004) Reference ballistic imaging database performance. Forensic Sci Int 140:207-215

Kirk PL (1953) Crime Investigation. Interscience Publishers Inc, New York, p 784 Kuppuswamy R (2011) Metallographic Etching of Aluminium and Its Alloys for Restoration of Obliterated Marks in Forensic Science Practice and Investigations, Aluminium Alloys, Theory and Applications, Prof. Tibor Kvackaj (Ed.)

Morgan RM, Bonzon JF, Nichols KH, Jellis T, Dunkerley S, Zelazowski P, Bull PA (2009) The Forensic Analysis of Sediments Recovered from Footwear. In: Criminal and Environmental Soil Forensics. Springer Netherlands, SpringerVerlag Berlin Heidelberg

Morrrz AR (1938) A New Method for the Examination of Markings on Bullets, Shell Cases and Breech Faces. The Police J 11:365-369

O'hara CE, Osterbtrn JW (1949) An Introduction To Criminalistics, vol 705. The Macmillan Co, New York

Rees CKR (1969) A Method for the Comparison of Tool Marks and other Surface Irregularities. J Forensic Sci Soc 9:153-155

Science and Practice Committee Report (1949) Use of "Faxfilm" in Law Enforcement Work, I.A.I. Proceedings 34th Annual Convention: 202-205

Sharma BR (1963) The Importance of Firing Pin Impressions in the Identification of Firearms. J Crim Law Criminol Police Sci 54:378-380

Smith TP, Smith GA, Snipes JBA (2016) Validation Study of Bullet and Cartridge Case Comparisons Using Samples Representative of Actual Casework. J Forensic Sci 61:939-946

Stephan C, Henneberg M (2001) Building Faces from Dry Skulls: Are They Recognized Above Chance Rates? J Forensic Sci 46:432-440

Tarko O (1948) A New Method for Comparing Fired Bullets. The Fingerprint \& Identification Magazine: 15-18

\section{Submit your manuscript to a SpringerOpen ${ }^{\circ}$ journal and benefit from:}

- Convenient online submission

Rigorous peer review

- Open access: articles freely available online

- High visibility within the field

- Retaining the copyright to your article

Submit your next manuscript at $\boldsymbol{\nabla}$ springeropen.com 